\title{
Plasma Electrolyte Polishing of Titanium and Niobium Alloys in Low Concentrated Salt Solution Based Electrolyte
}

\author{
Yuri ALIAKSEYEU*, Algimantas BUBULIS**, Vladimir MINCHENYA***, \\ Aleksandr KOROLYOV*, Vladimir NISS****, Rasa KANDROTAITE் JANUTIENE ***** \\ *State Enterprise "Science and Technology Park BNTU "Polytechnic",", Y. Kolas str. 24, Minsk 220013, \\ Republic of Belarus \\ **Institute of Mechatronics at Kaunas University of Technology, Studentu str. 56-106, Kaunas LT-51424, Lithuania \\ ***Department of Design and Production of Devices at Belarusian National Technical University, Nezavisimosty av. 65, \\ Minsk 220013, Republic of Belarus \\ ****Innovation and Production Center of Medical Equipment and Products at Belarusian National Technical University, \\ Nezavisimosty av. 65, Minsk 220013, Republic of Belarus \\ *****Department of Production Engineering at Kaunas University of Technology, Studentu str. 56-318, Kaunas LT- \\ 51424, Lithuania \\ crossref http://dx.doi.org/10.5755/j02.mech.25044
}

\section{Introduction}

By the reason of special properties, titanium and niobium alloys have become widely used in the manufacturing of a number of demanding products [1-5]. For example, the titanium and niobium alloys are used in aircraft construction, nuclear power industry, space engineering, microwave and ultrasonic technologies as well as in the medical products manufacturing [1, 6-9]. In most cases, the manufacturing technology of such products stipulates high-quality surface polishing. These products are, e. g., dental and bone implants, implants for traumatology, cranial plates, spinal fixators; turbine blades of aircraft engines made of titanium alloys; plates, foil and wire used for bonding tissues, nerves, stitching, prostheses production; parts of heatreleasing and heat-exchanging elements of nuclear-energy systems; parts of the colliders' accelerating structures.

Traditionally, mechanical and electrochemical methods are used for polishing products from titanium and niobium alloys. Disadvantages of the mechanical methods are low productivity, susceptibility to embedded particles introduction, difficulties in processing of intricate-shaped parts [10]. For the electrochemical technologies, the indicated materials are difficult to treat and polishing processes require usage of toxic electrolytes. Usually, electrochemical polishing of titanium and niobium alloys is carried out in acid electrolytes consisting of a solution based on toxic hydrofluoric acid (20-25\%) with the addition of sulfuric, nitric, and perchloric acids $[11,12]$. Such solutions are unsafe, the use of hydrofluoric acid throughout the world is strictly regulated. In recent years, electrolytes based on fluorine salt solutions in organic solvents such as methanol or dimethylformamide (being also toxic) have been developed [13, 14].

In order to reduce the environmental load, electrolyte-plasma treatment is possible to use as an alternative to the existing methods of electrochemical polishing. The electrolyte-plasma treatment technology is developed for polishing (plasma-electrolyte polishing - PEP), deburring and cleaning of metal products and also for improvement chemical, mechanical and physical properties of the surface [15, 16]. In addition, the electrolyte-plasma treatment is used for electrolytic heating and electrochemical-thermal hardening of the surface [17]. The electrolyte-plasma treatment is performed at a voltage above $200 \mathrm{~V}$. The electrolyte-plasma treatment mode corresponds to the section $\mathrm{BC}$ on the current-voltage characteristic of the anode process in the electrolyte (Fig. 1). In practice, the operating voltage is 280$300 \mathrm{~V}$ at the current density of $0.1-0.4 \mathrm{~A} / \mathrm{cm}^{2}$. Salts solutions with a concentration of $3-6 \%$ are usually used as electrolytes.

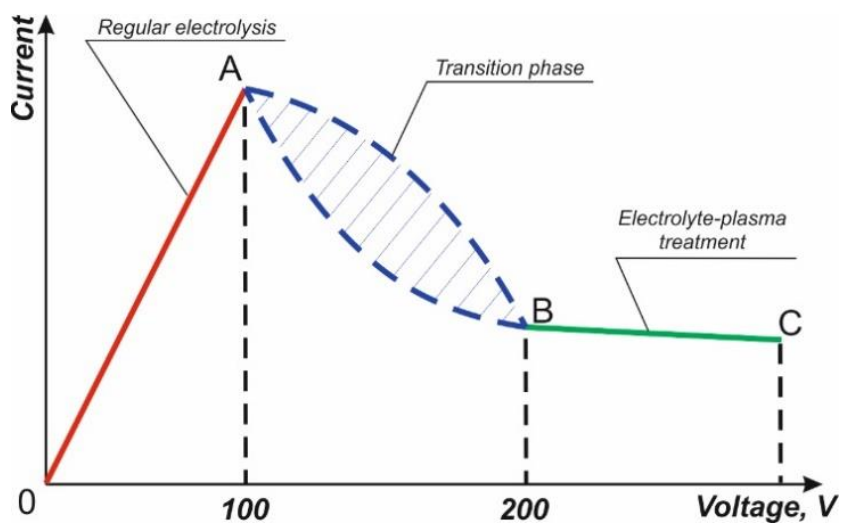

Fig. 1 Dependence between current and voltage of anodic process

The PEP compared to mechanical and electrochemical polishing has a number of significant advantages: high environmental friendliness compared to electrochemical polishing due to the use of electrolytes based on aqueous solutions of salts; processing parts and products of any configuration; obtaining a mirror surface with a roughness up to $R a=0.01 \mu \mathrm{m}$; elimination of nonconforming surface layer and residual stresses, improving physical, mechanical and chemical properties of the surface; sufficiently short duration of the polishing process; significant reduction in manual labour; processing high-hard and viscous materials [18]. However, the mass PEP technology usage is limited by the fact that on an industrial scale the PEP processes have only been developed for a small list of materials: low-carbon and corrosion-resistant steels, aluminium alloys, bronze and brass. The technologies for processing such materials as, for example, titanium and niobium, have been worked out only in laboratory-like conditions [19] and have not been widely 
used in industry.

In order to solve these problems, in this paper we shall propose to use fundamentally new modes of PEP of products from titanium and niobium alloys using simple electrolytes based on an aqueous solution of fluoride salt, the use of which can significantly increase the surface quality class. The advantage of the technology over classical electrochemical polishing is its safety due to the use of an electrolyte based on an aqueous solution of salt. The developed electrolyte is easily adjusted making possible to apply the process for treating articles made of titanium and niobium alloys on an industrial scale.

The aim of the paper is to study the characteristics and morphology of the surface after processing using the developed method.

\section{Experimental}

The research was carried out on flat samples of commercially pure titanium Grade 2 with the dimensions of $30 \times 15 \times 1.5 \mathrm{~mm}$ and commercially pure niobium $\mathrm{Nb}-1$ with the dimensions of $20 \times 30 \times 2 \mathrm{~mm}$. The titanium samples were preliminarily treated with $\mathrm{SiC}$ grinding paper with $\mathrm{P} 600$ grain, the niobium samples - with P300 grinding paper. The average surface roughness $R a$ of the initial titanium and niobium samples was 0.365 and 0.706 microns, respectively.

A specially developed experimental device was used to perform PEP. The device included a working bath (cathode) 6, a heater 2, a heat exchanger 4 , a temperature sensor 5 and an electrolyte mixing system 3 (Fig. 2).

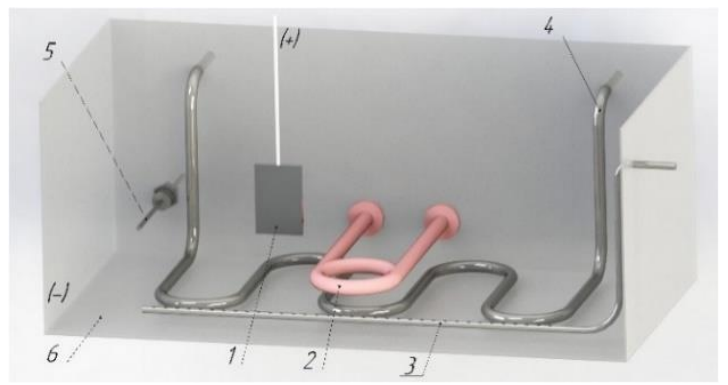

a

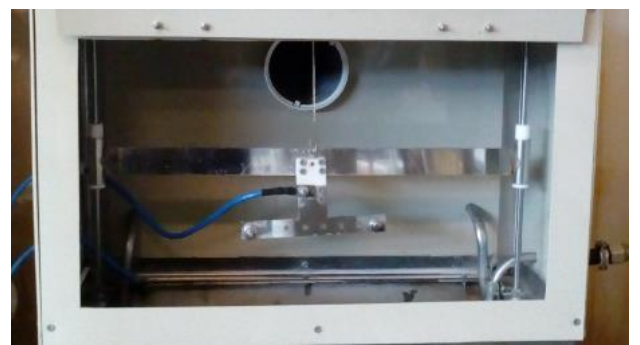

b

Fig. 2 PEP research equipment. Working bath scheme a): 1 - sample; 2 - heater; 3 - electrolyte mixing system; 4 - heat exchanger; 5 - temperature sensor; 6 - working bath; b) Real view of an experimental setup

PEP of samples was made in aqueous solution of ammonium fluoride $\left(\mathrm{NH}_{4} \mathrm{~F}\right)$ with a concentration of $4 \%$. The value of the operating voltage varied in the range from $260 \mathrm{~V}$ to $300 \mathrm{~V}$ in increments of $10 \mathrm{~V}$. Each sample was treated for $2 \mathrm{~min}$. While studying the impact of voltage on the processing efficiency, surface quality, processing productivity, the temperature of electrolyte was $90^{\circ} \mathrm{C}$, the processing time was $1 \mathrm{~min}, 3 \mathrm{~min}$ and $5 \mathrm{~min}$. While studying the impact of current density on processing efficiency, surface quality, processing productivity, current density control was performed by changing the electrolyte temperature in the range from $75^{\circ} \mathrm{C}$ to $95^{\circ} \mathrm{C}$ (voltage value was $300 \mathrm{~V}$, processing time $-3 \mathrm{~min}$ ).

The productivity assessment was performed by changing the mass of the samples as a result of processing. The mass of the samples before and after processing was determined using the Ohaus Pioneer PA214 analytical balance. The current was determined using the UNIT-203 current clamp. The current density was set as the ratio of the current to the area of the treated surface. The processing efficiency under different conditions was determined as the ratio of the roughness change to the specific mass of the removed material during the processing of $\Delta R a / \Delta m_{s p}$.

Micrographs of the samples' surface before and after PEP were obtained with a scanning electron microscope VEGA II LMU with INCA350 microanalyzer.

\section{Results and Discussion}

Results of PEP of flat specimens of titanium and niobium are presented in Fig. 3.
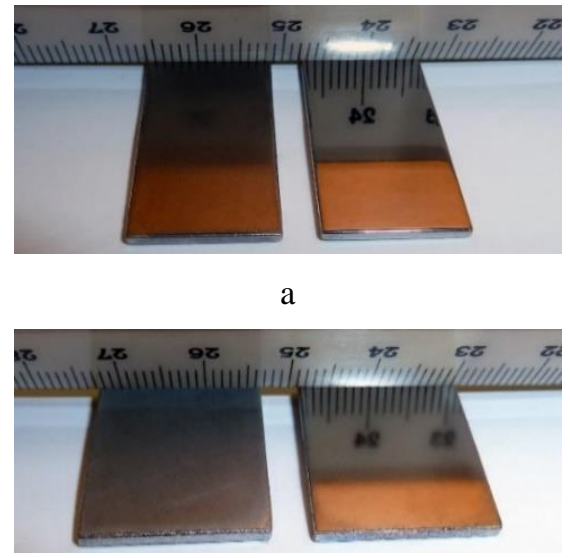

b

Fig. 3 Results of PEP on flat samples of titanium and niobium: a) on titanium; b) on niobium

Fig. 4 shows the dependence between current density and operating voltage (voltage-current characteristics) in the titanium and niobium PEP, for various temperatures of the electrolyte. It can be seen from the dependences that with increasing voltage the current density decreases insignificantly, which is typical for the processes of electrolyticplasma treatment. This is due to the fact, that with the increase of operating voltage, the energy released in the vapor-gas shell increases, which leads to the growth in the anode temperature and an increase of thickness of the vaporgas shell. The current density for niobium corresponds to the same current density values for the processing corrosion-resistant steels in $4 \%$ ammonium sulfate solution according to the data obtained in [18]. Comparison of the dependencies in Fig. 4, a and b, shows that the current density for the titanium samples is higher than for the niobium samples. Thus, due to the obtained experimental data, for example, at electrolyte temperature of $90^{\circ} \mathrm{C}$, current density while titanium samples processing is in average $20 \%$ higher than for niobium. In addition, it must be pointed out, that the current- 
voltage characteristics for titanium are much sloping than for niobium. Accordingly, the influence of voltage on the current density for titanium is less noticeable.

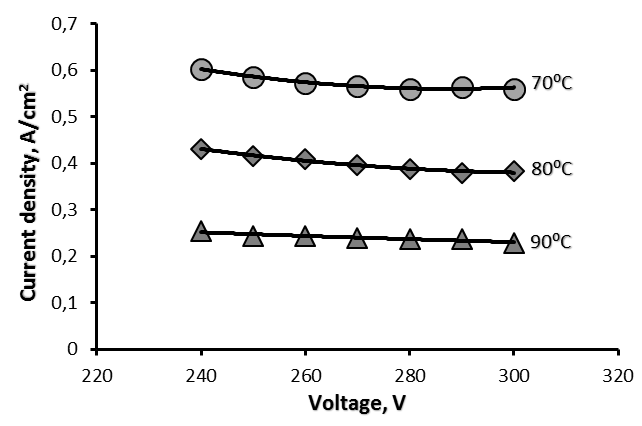

a

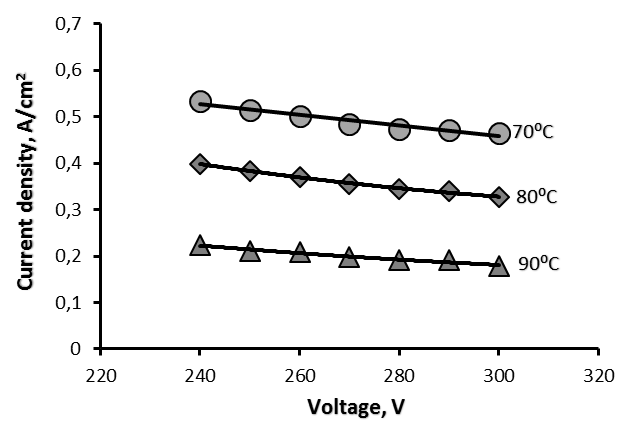

b

Fig. 4 The effect of voltage on current density at various temperatures of electrolyte: a) for titanium; b) for niobium

Experimental dependences of the specific removal rate $\Delta m_{s p}$ of the mass on the operating voltage obtained for the titanium and niobium samples during treatment with different duration are shown in Fig. 5. As the voltage increases, the processing capacity decreases. The dependences of the specific removal rate on the voltage for the titanium (Fig. 5, a), as in case with dependences between current density and voltage (Fig. 4, a), are more sloping compared to the similar dependences for niobium (Fig. 4, a, and Fig. 5, b), that is, the correlation between the current density and metal removal is maintained in accordance with the Faraday's law.

The decrease in PEP efficiency with the increase in operating voltage does not cause the quality reduction of the formed surface, in particular, roughness parameter $R a$. Fig. 6 shows experimental dependences demonstrating the dynamics of the surface roughness $R a$ changes while the titanium and niobium samples processing. From the obtained dependences, it is obvious, that with the increase in operating voltage in the analyzed range (from $260 \mathrm{~V}$ to $300 \mathrm{~V}$ ), reduction of the achievable values of the surface roughness parameter $R a$ is provided. At the same time, etching and increase in roughness occurs as a result of niobium processing at voltage of $260 \mathrm{~V}$ instead of surface polishing, and the value of the roughness parameter $R a$ intensively grows with increasing processing time (Fig. 6, b).

In the processes of electrochemical processing (including electrolyte-plasma treatment), the metal removal from the surface is carried out under Faraday's law, according to which, the volume (or mass) of the metal removed from the blank is directly proportional to the electric charge passed through the electrolyte. Thus, the higher the current density, the higher the processing capacity. The experimental dependences of the specific removal on the current density for titanium and niobium are shown in Fig. 7. The obtained dependences are linear. The metal removal rate grows with increasing of current density. In this case, the specific removal for niobium samples is almost twice as high as that for titanium, which is associated with higher values of the electrochemical equivalent $(\mathrm{Ti}-0.162 \mathrm{mg} / \mathrm{K}$, $\mathrm{Nb}-0.192 \mathrm{mg} / \mathrm{K}$ ) [20] and, presumably, with the current efficiency coefficient.

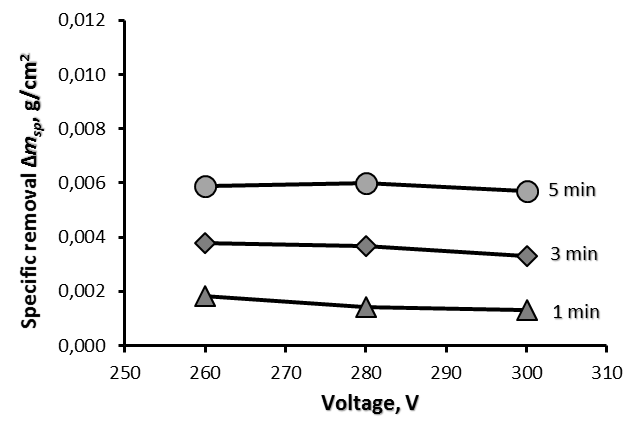

a

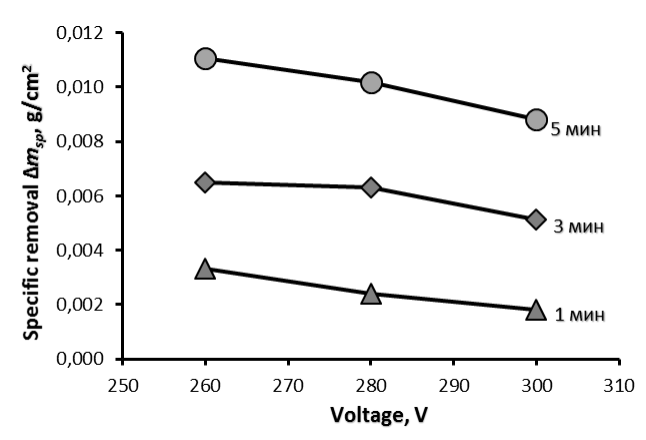

b

Fig. 5 Effect of voltage on metal removal: a) for titanium; b) for niobium

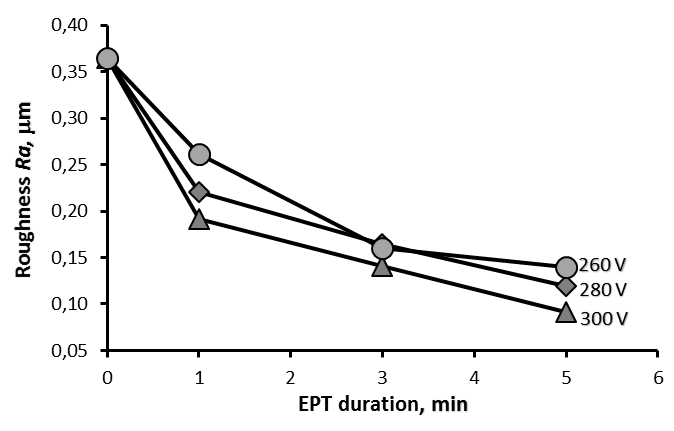

a

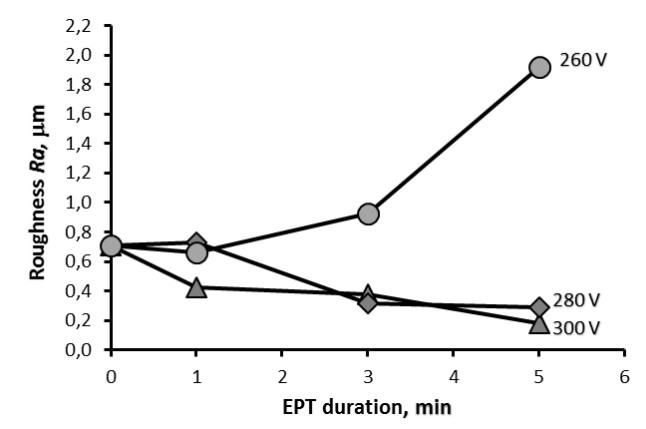

b

Fig. 6 Effect of processing time on roughness: a) for titanium; b) for niobium 


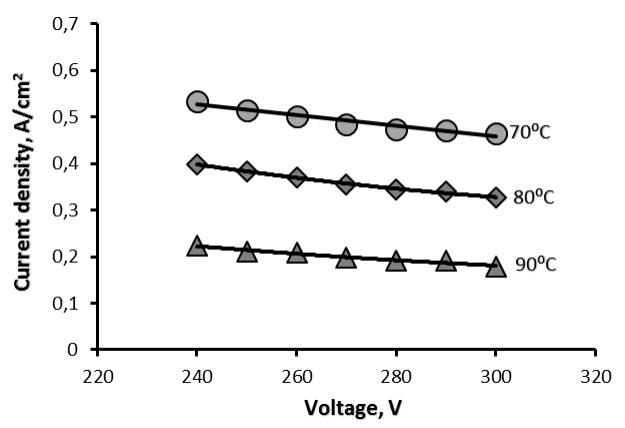

Fig. 7 Effect of current density on specific removal

Fig. 8 shows the dependence of the surface roughness variation of titanium and niobium samples on the current density. In the analyzed range of current density (for titanium - 0.18-0.45 A/ $\mathrm{cm}^{2}$, for niobium - 0.19$0.48 \mathrm{~A} / \mathrm{cm}^{2}$ ), the experimentally established values of the surface roughness change $\Delta R a$ have a significant spread both for the titanium and niobium samples. Simultaneously,

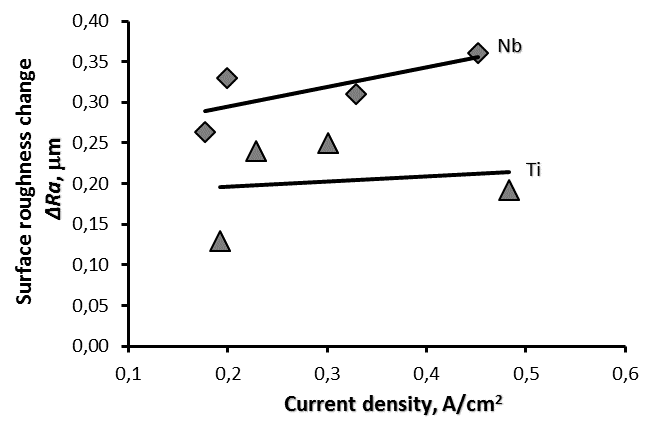

Fig. 8 Dependence of roughness change on current density

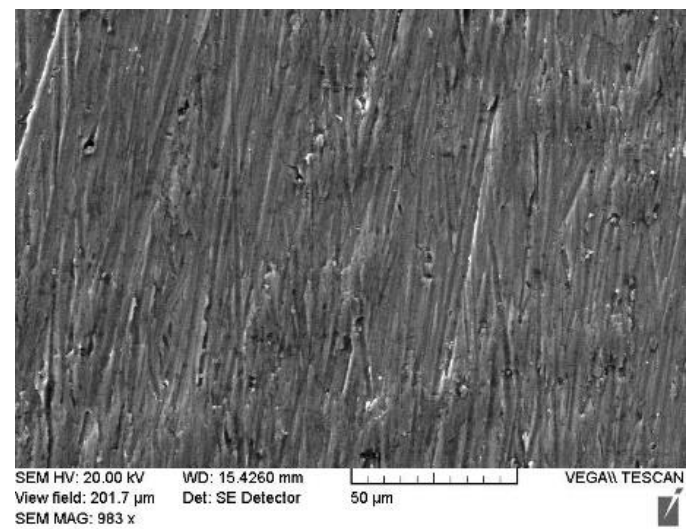

a

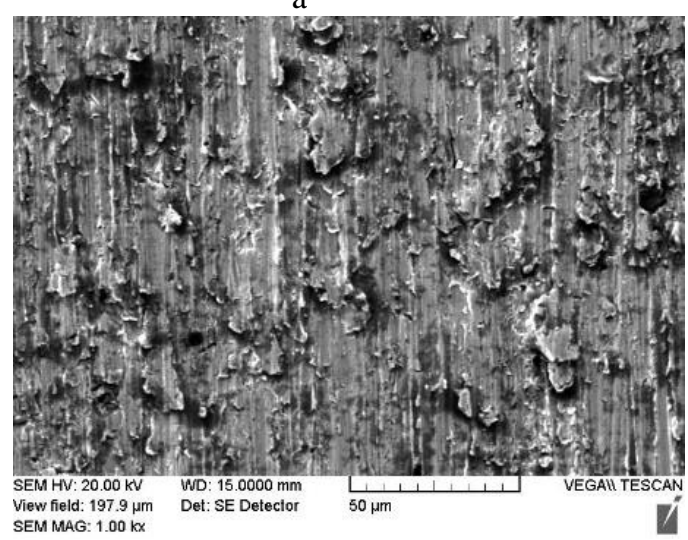

c a tendency of insignificant increase in the value of the surface roughness change with increasing of current density is observed. The values $\Delta R a$ for niobium are much higher than the analogues values for titanium.

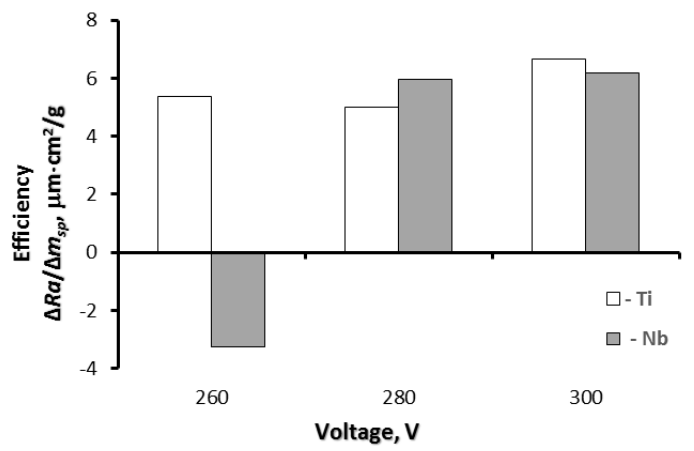

a

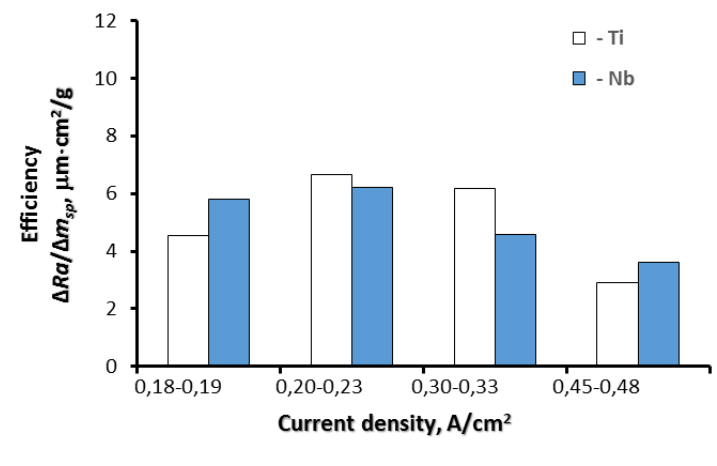

b

Fig. 9 Effect of electrical characteristics on effectiveness of PEP

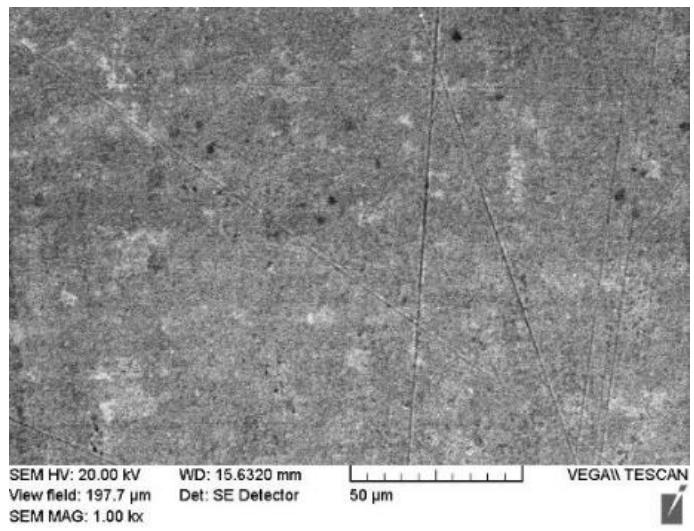

b

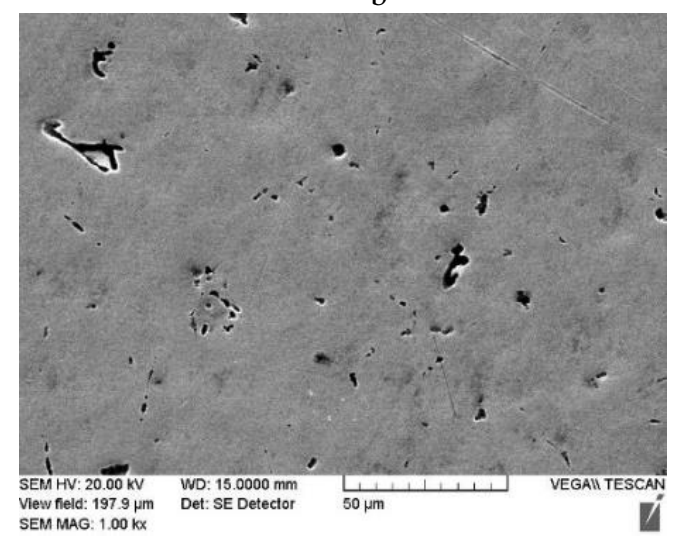

d

Fig. 10 Micrographs of the surface of samples: $a$ - titanium before PEP; $b$ - titanium after PEP; $c$ - niobium before PEP; $d$ - niobium after PEP 
Fig. 9 shows the diagrams characterizing the influence of operating voltage and current density on the efficiency of processing of titanium and niobium on the change in roughness. The surface treatment efficiency indicators $\Delta R a / \Delta m_{s p}$ for both titanium and niobium have approximately equal values, except for the value obtained for niobium at voltage of $260 \mathrm{~V}$ when the efficiency is negative. Analysis of the presented diagrams shows that in order to achieve high efficiency, it is also necessary to perform processing at the following modes: for titanium - at voltage $300 \mathrm{~V}$, current density $0.18-0.30 \mathrm{~A} / \mathrm{cm}^{2}$, for niobium - at voltage $280-300 \mathrm{~V}$, current density $0.18-0.20 \mathrm{~A} / \mathrm{cm}^{2}$.

Micrographs of the surface of titanium and niobium samples before and after treatment are shown in Fig. 10. The surface of titanium before the PEP (Fig. 10, a) is characterized by the presence of longitudinal stripes formed as a result of preliminary grinding of the samples. After the PEP, the surface is smoothed out, only traces from the deepest scratches are observed (Fig. 10, b). The surface of the original samples of niobium, in addition to the longitudinal stripes, obtained during grinding, is also characterized by the presence of sufficiently large scores with dimensions up to $12 \mu \mathrm{m}$ (Fig. 10, c). As a result of the niobium PEP a smooth surface with a small amount of pitting up to $5 \mu \mathrm{m}$ in size (Fig. 10, d) is formed.

Based on the results obtained, PEP processes have been worked out for products made of titanium alloys, used in medicine and turbine construction. Examples of the products treated using the developed technology are shown in Fig. 11.

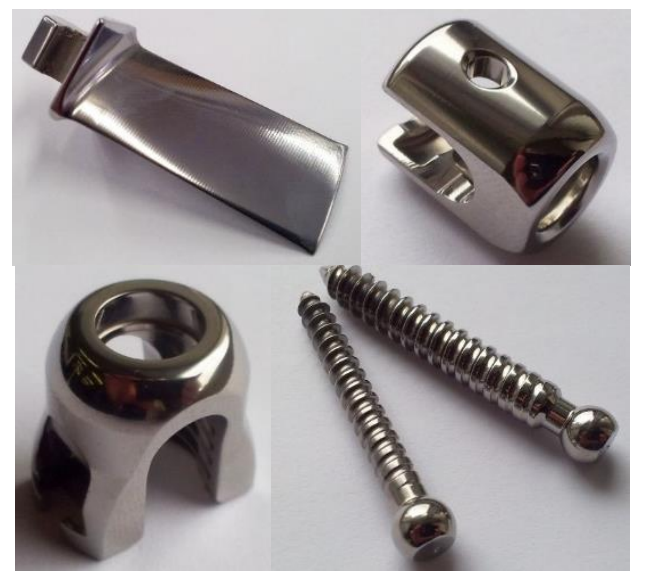

Fig. 11 Examples of PEP treated articles made of titanium alloys

\section{Conclusions}

1. A new method of plasma-electrolyte polishing (PEP) of titanium and niobium alloys has been developed. It is characterized by high environmental friendliness compared to classical electrochemical polishing due to the use of harmless electrolytes based on aqueous solutions of salts with a total concentration of no more than $6 \%$. By contrast, traditional polishing, for example, of titanium alloys is performed in electrolytes with temperature of at least $80^{\circ} \mathrm{C}$, containing in addition to sulphuric, nitric acids and perchloric acids also, toxic hydrofluoric acid with a concentration of $20-25 \%$.

2. It was found that with increasing operating voltage in the analysed range (from $260 \mathrm{~V}$ to $300 \mathrm{~V}$ ) during PEP process the achievable values of the surface roughness parameter $R a$ are reduced. At the same time, as a result of niobium processing at voltage of $260 \mathrm{~V}$ instead of polishing, the surface is etched with an increase of roughness, and the roughness value $R a$ intensively increases with increase in processing time. In the case of titanium PEP, with an increase in the operating voltage, a gradual increase in the value of the surface roughness change $\Delta R a$ is observed throughout the analysed range. The greatest roughness change $\Delta R a$ in the niobium processing is achieved in the range of voltage values from $280 \mathrm{~V}$ to $300 \mathrm{~V}$.

3 . Based on the results of the study of the influence of current density on the quality of titanium and niobium PEP, it was determined that with the increase of current density in the analysed range of values (for titanium - 0.18 $0.45 \mathrm{~A} / \mathrm{cm}^{2}$, for niobium $-0.19-0.48 \mathrm{~A} / \mathrm{cm}^{2}$ ), there is a tendency for an insignificant increase in the value of the surface roughness change $\Delta R a$ for both, titanium and niobium. In this case, the values of $\Delta R a$ for niobium are much higher than the analogous values for titanium.

4. The highest values of the PEP efficiency are achieved within the following modes: for titanium - at voltage $300 \mathrm{~V}$, current density $0.18-0.30 \mathrm{~A} / \mathrm{cm}^{2}$, for niobium at voltage $280-300 \mathrm{~V}$, current density $0.18-0.20 \mathrm{~A} / \mathrm{cm}^{2}$.

\section{References}

1. Veiga, C.; Davim, J. P.; Loureiro, A. J. R. 2012. Properties and applications of titanium alloys: a brief review, Reviews on Advanced Materials Science 32(2): 133148.

2. Heisterkamp, F.; Carneiro, T. 2002. Niobium: Future Possibilities-Technology and the market place [online]. Available from Internet: https://www.semanticscholar.org/paper/NIOBIUM\%3A-FUTURE-POSSIBILITIES-\%E2\%80\%93TECHNOLOGY-AND-THE-Heisterkamp-Carneiro/290b075619236b067b4556327331f2434ec882ad \#citing-papers.

3. Boyer, R. R. 2010. Attributes, characteristics, and applications of titanium and its alloys, JOM Journal of the Minerals, Metals and Materials Society 62(5): 21-24. https://doi.org/10.1007/s11837-010-0071-1.

4. Inagaki, I.; Takechi, T.; Shirai, Y.; Ariyasu, N. 2014. Application and features of titanium for the aerospace industry, Nippon steel \& SUMITOMO metal technical report No 106: 22-27 [online]. Available from Internet: https://www.nipponsteel.com/en/tech/report/nssmc/pdf/106-05.pdf.

5. Nikishina, E. E.; Drobot, D. V.; Lebedeva, E. N. 2013. Niobium and tantalum: State of the world market, fields of application, and raw sources, Part I. Russian Journal of Non-Ferrous Metals 54(6): 446-452. https://doi.org/10.3103/S1067821213060187.

6. Froes, F. H.; Imam, A. M. 2010. Cost affordable developments in titanium technology and applications, Key Engineering Materials 436: 1-11. https://doi.org/10.4028/www.scientific.net/kem.436.1.

7. Zardiackas, L. D.; Kraay, M. J.; Freese, H. L. 2006. Titanium, niobium, zirconium, and tantalum for medical and surgical applications, West Conshohocken, PA: ASTM International. https://doi.org/10.1520/STP1471-EB. 
8. O'Brien, B.; Stinson, J.; Carroll, W. 2008. Development of a new niobium-based alloy for vascular stent applications, Journal of the mechanical behavior of biomedical materials 1(4): 303-312.

https://doi.org/10.1016/j.jmbbm.2007.11.003.

9. Antoine, C. Z.; Villegier, J. C.; Martinet, G. 2013. Study of nanometric superconducting multilayers for RF field screening applications, Applied Physics Letters 102(10): 102603. https://doi.org/10.1063/1.4794938.

10. Axinte, D. A.; Kwong, J.; Kong, M. C. 2009. Workpiece surface integrity of Ti-6-4 heat-resistant alloy when employing different polishing methods, Journal of materials processing technology 209(4): 1843-1852. https://doi.org/10.1016/j.jmatprotec.2008.04.046.

11. Tian, H.; Corcoran, S. G.; Reece, C. E.; Kelley, M. J. 2008. The mechanism of electropolishing of niobium in hydrofluoric-sulfuric acid electrolyte, Journal of the Electrochemical Society 155(9): D563-D568. https://doi.org/10.1149/1.2945913.

12. Ford, D. C.; Cooper, C.; Cooley, L. D.; Thompson, C.; Bouchard, D.; Albee, B.; Bishnoi, S. 2013. Chemical Analysis of Fluorine in Niobium Electropolishing, Journal of the Electrochemical Society 160(6): H398$\mathrm{H} 403$. https://doi.org/10.1149/2.144306jes.

13. Tajima, K.; Hironaka, M.; Chen, K. K.; Nagamatsu, Y.; Kakigawa, H.; Kozono, Y. 2008. Electropolishing of CP titanium and its alloys in an alcoholic solutionbased electrolyte, Dental materials journal 27(2): 258265. https://doi.org/10.4012/dmj.27.258.

14.Simka, W.; Mosialek, M.; Nawrat, G.; Nowak, P.; Żak, J.; Szade, J.; Szyk-Warszyńska, L. 2012. Electrochemical polishing of $\mathrm{Ti}-13 \mathrm{Nb}-13 \mathrm{Zr}$ alloy, Surface and Coatings Technology 213: 239-246. https://doi.org/10.1016/j.surfcoat.2012.10.055.

15. Zeidler, H.; Boettger-Hiller, F.; Edelmann, J.; Schubert, A. 2016. Surface finish machining of medical parts using Plasma Electrolytic Polishing, Procedia CIRP 49: 83-87. https://doi.org/10.1016/j.procir.2015.07.038.

16. Nestler, K.; Böttger-Hiller, F.; Adamitzki, W.; Glowa, G., Zeidler, H.; Schubert, A. 2016. Plasma Electrolytic Polishing - an Overview of Applied Technologies and Current Challenges to Extend the Polishable Material Range, Procedia CIRP 42: 503-507. https://doi.org/10.1016/j.procir.2016.02.240.

17. Aliakseyeu, Y. G.; Korolyov, A. Y.; Niss, V. S.; Parshuto, A. E. 2013. Characteristics of electrolyticplasma heating at electrochemical-heat treatment of steel, Science \& Technique 6: 20-24 (in Russian).
18. Aliakseyeu, Y. G.; Korolyov, A. Y.; Parshuto, A. E.; Niss, V.S. 2012. Model of metal removal in electrolyticplasma treatment of the cylindrical surfaces, Science \& Technique 3: 3-6 (in Russian).

19. Smyslov, A. M.; Smyslova, M. K.; Mingazhev, A. D.; Selivanov, K. S. 2009. Multistage elektrolitplasma processing of products from the titan and titanic alloys, J. Herald of Ufa State Aviation Technical University 13, 1(34): 141-145 (in Russian).

20. Amitan, G. L. Reference on electrochemical and electrophysical processing methods, Edit. V.A. Volosatov. Leningrad: Mashinostroenie, 1988. 719 p. (in Russian).

Y. Aliakseyeu, A. Bubulis, V. Minchenya, A. Korolyov, V. Niss, R. Kandrotaite Janutienè

\section{PLASMA ELECTROLYTE POLISHING OF TITANIUM AND NIOBIUM ALLOYS IN LOW CONCENTRATED SALT SOLUTION BASED ELECTROLYTE}

S u m m a r y

Today, world enterprises specializing in the production of titanium and niobium alloy products and having modern high-tech equipment are still forced to use outdated, costly and environmentally unsafe methods of polishing and surface cleaning, based on electrochemical treatment in toxic solutions. The complex geometric shape of the processed products does not allow the use of mechanical polishing methods, due to high labor costs and low efficiency. These materials are difficult to process, and the processes of their polishing require the use of toxic electrolytes. An alternative to existing methods of electrochemical polishing is plasma electrolyte polishing in aqueous solutions of salts with a concentration of up to $5 \%$. We have developed fundamentally new modes of plasma electrolyte polishing of products from titanium and niobium alloys using simple electrolytes based on an aqueous solution of fluoride salt, the use of which can significantly increase the surface quality class. The advantage of the plasma electrolyte polishing over classical electrochemical polishing is its safety due to the use of an electrolyte based on an aqueous solution of salt. The paper presents the results of an investigation of the characteristics and morphology of the surface after processing using the developed method. Modes that provide the maximum change in roughness with minimal metal removal were obtained.

Keywords: plasma, polishing, metal treatment, titanium, niobium, alloy, smoothing, roughness.

Received February 03, 2020

Accepted February 17, 2021

This article is an Open Access article distributed under the terms and conditions of the Creative Commons Attribution 4.0 (CC BY 4.0) License (http://creativecommons.org/licenses/by/4.0/). 